\title{
Ceramic education transformation and drive porcelain art design innovation and development
}

\author{
Xiu-mei Wu \\ School of Art Design, Jingdezhen Ceramic Institute, Jingdezhen 333403 China
}

Keywords: education of pottery and porcelain, porcelain industry transformation, art and design

\begin{abstract}
. the revival of the arts and crafts as a cultural ideological trend, cannot fundamentally change the trend of high-tech manufacturing, but as a culture we have to protect and to use, and make full use of modern science and technology will develop the traditional process of transformation, otherwise, will not be able to adapt to the development of modern traditional demand. Traditional manual ceramic is a precious property of Chinese traditional culture, however, with the development of science and technology, the traditional manual ceramic gradually replaced by industrial products, many traditional handmade ceramic was waning, and even die. Therefore, how to protect traditional handmade ceramic, make it adapt to the requirement of times development, and development is an urgent need to inheritance and transformation. Ceramic education development to some extent to reverse this trend, therefore, the development of ceramic education is the basic power reform ceramics industry and design innovation.
\end{abstract}

\section{The development of modern ceramic transformation of ceramic education role in promoting}

The development of modern ceramic transformation way. Traditional handicraft transformation development is the inevitable result of the development of social production mode, some scholars think that the traditional folk arts and crafts should restore to production under its basic form, can not blindly industrialization and mass production and commercialization. The author think that things are constantly moving forward, in order to improve labor efficiency, make full use of high-tech development is also necessary to transform, otherwise, under the modern high-tech development, living standards increasing quickly, the diversification of consumption idea today, traditional will lose its development space. Therefore, the transformation of traditional handicraft development is the inevitable law of historical development, because of being under the influence of various factors to lead to its transformation.

Ceramic is China's oldest traditional manual products, its production has a long history, is necessary in People's Daily life, today, in the unprecedented development of plastic products, ceramic products to win market reform must be carried out in the transformation of development. In fact, many are now trying to take measures to transform traditional industry, ceramic is not exceptional also, this kind of transformation method is mainly manifested in the following aspects:

First of all, set the overall resources, make porcelain form cluster development. Under the rapid development of modern high-tech and information technology, resource sharing is the source of enterprise development, the resources sharing in addition to the longitudinal joint between each ceramic enterprises, also can form ceramic materials required for the processing technology of horizontal joint industry, make the whole porcelain formed a cross-industry community resources, make the ceramic enterprises form combining the model, the road to development through clustering makes the enterprise to do strongly does, which is one of the ceramic industrial development strategy. Decorative materials such as ceramics, ceramics in the development of both life of porcelain and ceramics used in construction, its design and color is more and more rich and colorful, this is to make full use of information technology and high technology, the unprecedented development of printing industry to promote the diversification of the ceramic decoration. Ceramics completely, therefore, can make use of the new technology of printing industry innovation and development in the ceramic decoration, and print form clustering model of development, need, 
common development 。

Second, make full use of high-tech, accelerate the innovation development of porcelain. In the modern, high-tech widely applied to various fields, the traditional process to adapt to the request of the ages must fully use high-tech to continue to develop the transformation and upgrading. Foshan ceramics in the process of the development of a good with the aid of the USES of technology to conduct a comprehensive production, they make full use of high-tech, industrial upgrading. As we know, promote the development of China's innovation is the fundamental driving force of the development of the ceramic industry, ceramic the sustainable development of the traditional industry technology innovation must revolve around, from the ceramic material and design innovation and development, especially the key technology innovation and the formation of system integration, make new technology use in ceramic production form large-scale, highly efficient and intelligent development of ceramics industry, on craft form high-tech industrial chain, promote the ceramic industry restructuring and upgrading, so as to effectively improve the added value of ceramic products。

Make full use of high-tech ceramics industry innovation and development is mainly manifested in the following parts: first, in the process of high-tech application. For thousands of years to dig the mass production of ceramic making high territory quality worse and worse, therefore, must make full use of high-tech to ceramic raw materials for processing in order to achieve the greatest degree of refining quality kaolin. In addition, the ceramic forming process is also gradually realize the high-tech industrialization production, such as rolling, molding pressure, static pressure, high pressure grouting, grouting pressure molding machine can produce as different of different form and embossed ceramics. Second, on ceramic decoration design is the design and implementation of the use of high-tech. In modern times, the adornment of the ceramic art more and more diversified, brush, decals, printing, etc., through the use of high-tech, modern high precision screen printing can print all kinds of ever-changing decals. For some ceramics, such as the winning entries of art creation can use modern technology, using computer color and matching color screen printing, high simulation to show the original image, and reach the mass production。

Finally, give full play to the function of the tourism industry, expand the visibility and sales of porcelain. Tourism combined with the traditional industry development is one of the strategies of the development of traditional industry transformation in today's world, through the development of the tourism industry to expand the traditional industry of popularity, however, the existing tourism development, the most traditional handicraft in a "supporting role" position, its rich cultural connotation and cultural value. China is different from other traditional industries, however, because like jingdezhen porcelain and foshan and other places of China have formed the entire city of porcelain industry production, it could in the very great degree by China to develop the tourism industry, so China development compared with the tourism industry, held a dominant position is, thus it can be through tourism enlarge the popularity and sales of porcelain, looking for new development opportunities for the porcelain industry。

The decline of traditional arts and crafts is the inevitable outcome of the transformation of modern society, thus the traditional craft to continue development, first, must adapt to The Times demand, constant innovation, make the traditional craft and modern life, satisfy and adapt to the needs of modern life, and will live for the production of traditional crafts every aspect of life. Second, through the enterprise transformation to adapt to modern social and economic development, and form the industrial chain and other industries collection development. Third, make full use of modern means of science and technology, the development of new materials, production of the modern cultural aesthetic demand of new products.

\section{The relationship between transformation of ceramic education and ceramic development}

Ceramic education is the driving force for the development of ceramic transformation, the development of education is the source of innovation cannot leave the mind of the ceramic, the school is a sacred place of talent training, the innovation of the ceramic art designer is the best of 
the leading ceramic enterprises to carry out transformation and upgrading of the booster. We all know that ceramic enterprise products, has a life cycle stage development period and introducing basic are cast money without profits, profit growth and maturation only slowly, and once mature products, will lead to the counterpart of counterfeit or competition, market competition motivation, resulting in a decline in prices and thus into recession was withdrawn from the market. Product, therefore, to keep profits, must constantly in product profit peak for the replacement of product life cycle, which is constantly upgrading design, thinking, to find more value. From this point, excellent ceramic design team plays a key role, ceramic school talent cultivation is the ceramic enterprises outstanding talent training base, the transformation of ceramic enterprises development depends on good ceramic talents of innovative thinking 。

The characteristics of modern ceramic art innovation. Into contemporary, high-tech development and lifestyle change and frequent contact with the world, to the influence of the ceramic design demands of its, have both national factors, and to qualify for the world and contemporary aesthetic standard, method of blue porcelain can be said to do this, it will be the traditional craft with today's life, fashion and aesthetic for cross-border cooperation, it will be the development of industrialization, jingdezhen folk traditional crafts, blend in contemporary design and industry to the preservation and perpetuation of traditional culture, and making the conforms to the modern aesthetic demand of ceramic products, in the blue porcelain products everywhere embodies the fashion, personalized and environmental protection, etc 。

First, fashionable and personalized. Method of blue porcelain fashionable whole world why? Because it is a blend of western aesthetic, in the design of both the western elements, and to have the Oriental flavor, inherits the national tradition, and into the modern young people's fashion personalized elements, that is its success, innovation and development in the traditional, to seek in the traditional contemporary feeling. Such as method of blue porcelain cooperation with the United States the Walt Disney company and the teapot teacup, designer of Mickey Mouse, Donald Duck and winnie the pooh animation classic image, full of tong qu, make everybody like animation image lifelike combined with porcelain, which is fully absorb young people and children love of Disney animation image to design, make the method of blue porcelain is full of fashion sense and personalization. Blue porcelain this fashion also performance in its handling of the graceful lines, method of blue porcelain both animals or plants on the proper use of lines to achieve dynamic beauty in sense of form, the beauty of this dynamic very has the characteristics of fashion, and on the handling of animal forms it sometimes use of exaggeration, making the products but also has the personalized characteristic 。

Second, pay attention to the detail processing. Contemporary ceramic design not just meet the needs of practical, pay more attention to the aesthetic side, therefore in design requires more delicate, especially pays attention to the processing of detail. The details of the handling performance on the modelling of fine on one hand, on the other hand performance on local colour. On modelling has not as a single round, but to learn from traditional form combines natural animals and plants and other forms of innovation, especially pay attention to the processing of detail, make the ceramics for daily use in modelling more rich and able to bear or endure look. Is not the whole shape and colour confined to a kind of color relations, but on the whole colour foils with fine colour ornament, pay attention to the whole tonal grasp. Such as method of blue porcelain porcelain sculpture in plants and animals, and every local animals, show the lifelike electromotive force, such as the 2002 "butterfly dance" series, fine butterfly transition on colour is very natural, as if really, the meridians and flowers are a little bit of characterization, make whole porcelain to clever in artistic effect 。

Third, the rich diversity. Integration in the world in modern times, diversity is the necessity of the development, daily-use ceramics in addition to its individuality and vogue design, the multiple performance to expand the scope of its sales, meet the needs of different consumer groups. Method of design of blue porcelain advocate intergrowth, symbiotic technology and art, tradition and innovation symbiosis, east and west symbiosis, make the design of products with diversity, suitable for different RACES, different nationalities, all kinds of consumer groups of different ages. Blue 
porcelain various forms and styles complement each other, interdependence, the tendency of unification in the contradiction, contradiction in unity performance, make the products present a rich and complex diverse state. Perhaps this is the success, a product to achieve the above various forms of symbiosis is very not easy, and method of blue porcelain made it, it is a blend of eastern and western people's aesthetic characteristics, found a common human like, that is the nature, surrounding the creation of the diversification of nature, so to meet all kinds of people, the consumers of different RACES 。

Fourth, advocate green environmental protection. Brought the rapid development of economic reform and opening up, however, the destruction of the natural resources and environment are the current problems worthy of thinking deeply in the late ninety $s$, people gradually realize the importance of environmental protection, because the green design is related to everyone's vital interests, in the design step by step and put forward the new concept of "green energy saving and ecological protection", advocate green design the ecological balance of the relationship between human and nature, as a result, every step in the process of design should fully consider the environmental problems, to minimize the damage to the environment 。

Ceramic itself is a blend of mud and fire, the material is environmental protection, modern ceramic products in satisfying practical function on the basis of the main consideration is still the problem of environmental protection. Method of blue porcelain design concept is derived from the scene and things of nature, the nature of the flower and grass swaying outline, pest birds play rhythm, animal fields is bold and unrestrained one by one on the work above, let a person see the beauty of harmony of all things, implements the chuang tzu's "heaven and earth and I and life, everything with me as a" philosophy. Method of blue porcelain company actively advocating environmental protection campaign, an environmental protection activity in Taiwan to create a set of "pandas, bamboo forests and birds" as the main elements of the dinnerware to promote environmental protection. In addition, the method of blue porcelain in design not only pay attention to environmental protection, also pay attention to environmental protection in the process, in order to compare with European bone porcelain, insist on not bone meal, eventually achieved through high-tech and as fully the effect of bone China 。

Fifth, combine with high-tech. Not only can make full use of high-tech design suitable for the development of the era of high-end porcelain, also can make the traditional manual porcelain to form a good training circulation of industrialization, in the early $1990 \mathrm{~s}$, the method of blue porcelain company spending a huge sum of money to introduce a new $3 \mathrm{~d}$ printers, the printer was only used in areas such as defense and car model design, method of blue porcelain company introduces the initial model of the printer to print porcelain. To have blue porcelain unique three-dimensional decoration, make picture adornment alive, even if this use of technology innovation and development. Visible, only make full use of modern high-tech to inherit and carry forward the traditional culture, make the traditional coruscate gives new vitality. In addition, the method of each working procedure of blue porcelain are fully revealed to the attention of the high-tech, such as designers must through the computer rendering drawings, and carved mold division with only not just accumulate over a long period of practical operation experience, in the process of production must use electronic technology to make the details of the porcelain parts more accurate, on the deployment of the adjustment of the shape and size of color porcelain is used a whole set of expensive computer modelling system。

\section{Ceramic education is the driving force of innovation design}

In today's society is represented by information technology and intelligent industrial revolution period, such as intelligent charging system, smart cars without a man to drive, $3 \mathrm{~d}$ printing breakthrough the limitation of the manufacturing and the bottleneck, a molding directly. The development of science and technology make traditional factory process disappeared, and the advantage of the past will be gradually replaced by the new trend, just a few years, the emergence of a new technology can change people's way of life, such as the emergence of WeChat reduced the 
people make a phone call, e-commerce make people don't have to go out shopping, pay treasure to the use of make people don't have to bring cash, go to the market to buy food... . Science and technology created a new industry, has a direct shot without innovation industry, large companies such as kodak, MOTOROLA said that have no have no, our ceramic industry also is in such an era. So ceramic innovation design is the direct source of ceramic enterprises to ensure fresh, ceramic education to cultivate talents than traditional ceramic more creative inheritance mode of craftsmen, the design of new products for ceramic created more value added, so the jingdezhen ceramic education shoulders the mission of bearing 。

\section{Conclusion}

Jingdezhen ceramic education experience of the official school development in one hundred, from the "school" to the "university" through the vicissitudes of life, from scratch, from local to international, which is bearing the weight of generations of leaders and great efforts, ceramic artist enjoys a good reputation in the international ceramic industry, said she was "ceramic huangpu school" is very appropriate. Her for Chinese ceramic enterprises conveying a batch of another batch of ceramic talents, also in the process of growing step by step. School "on the cultivation of talents pays attention to practice, pay attention to art workers in the professional disciplines, and in scientific research on industry demand, pay attention to the innovation in the artistic creation lead", in the field of ceramic is famous in the world, so to speak. This laid a solid foundation for Chinese ceramic to move towards the world. Jingdezhen ceramic institute of every step walk very forceful, steadfast, made great contribution to the cause of China's ceramics, in the process of development in the future, ceramic institute will not give up the spirit of courage. Still stick to further emancipate the mind, seeking truth from facts and keeping pace with The Times, blaze new trails, according to the scale, structure, quality and efficiency of the coordinated development of the principle, adhere to the connotation construction is given priority to, unswervingly and country, combining the regional economic construction and social development for the construction of the road, walked out of a contented courtyard characteristics of innovation development.

\section{Acknowledgments}

This work was financially supported by the jingdezhen ceramics university center for collaborative project: "jingdezhen ceramic art education from the evolution of modern times to contemporary".

\section{References}

[1] xiu-mei wu: the inheritance and change - jingdezhen porcelain development research of the republic of China, Beijing, guangming daily press, 2012, 5.

[2] xiu-mei wu: the traditional handicraft culture research - ceramic hangzhou fan, for example, Beijing: guangming daily press, 2013, 5.

[3] 8 zou jj: "whole tao designed founded" / / materials of jingdezhen history (12), the Chinese people's political consultative conference literature and history research committee, also the commission yaumcha county offset presses, 1996.

[4]XiChuan performance: "the classical works of design art anthology, nanjing: southeast university press, 2002.

[5] zhen-fan wan, Lin Songhua editor: studies of modern times social transformation in jiangxi, Beijing: China social sciences press, 2001.

Xiu-mei wu, female, doctor of design art, in fuzhou, master instructor, research direction: the art of design principle, industrial design and theory, ceramic art design and theory.

This paper is 